\title{
A Multi-Attribute Fuzzy Evaluation Model for the Teaching Quality of Physical Education in Colleges and Its Implementation Strategies
}

\author{
https://doi.org/10.3991/ijet.v16i02.19725 \\ Yao Wang, Chunyan Sun ${ }^{(凶)}$, Ying Guo \\ Cangzhou Normal University, Cangzhou, China \\ shierzu19810.163.com
}

\begin{abstract}
There are two major problems with teaching quality evaluation of physical education (PE) in colleges: the excessive number of evaluation factors, and the incomplete evaluation system. To solve the problems, this paper puts forward a multi-attribute fuzzy evaluation model of college PE teaching quality, and provides the strategies to implement the model. Firstly, the problems of college PE teaching were analyzed, and a novel multi-dimensional evaluation system was developed for college PE teaching quality. To quantify college PE teaching quality, an evaluation model of college PE teaching quality was established based on the Grey Relational Analysis (GRA). In addition, several strategies were presented to improve college PE teaching quality. The proposed model and strategies provide a good reference for solving similar complex system problems.
\end{abstract}

Keywords-Physical education (PE), teaching quality, colleges, evaluation model, grey relational analysis (GRA)

\section{Introduction}

With the progress of the implementation of quality education, the teaching mode of higher education for college students is being improved and developed constantly, and more attention has been paid to the problem of improving the quality of higher education [1-3]. As an important part of higher education, $\mathrm{PE}$ is playing a crucial role in the cultivation of college students' comprehensive ability [4-6], especially as modern society has valued college students' physical quality and taken it as an important evaluation factor of college students' comprehensive ability, administrators and workers engaged in higher education have gradually paid more attention to the quality of PE teaching in colleges, and the topic has also attracted the interests of scholars and experts; as a result, the problem of how to improve the quality of PE teaching in colleges and universities has become a hot issue in higher education research. For example: Forey et al. discussed the benefits brought by the explicit language teaching in PE class to the learning effect of PE lessons [7]. Gao analyzed and discussed the multiple PE teaching evaluation modes of common colleges and proposed a PE teaching evaluation index system 
accordingly [8]. Qin et al. analyzed the college PE teaching evaluation reform methods based on DEA model, and proposed corresponding implementation suggestions [9]. Targeting at improving the PE teaching quality, from the perspective of PE teachers, Zhao and Wang proposed an evaluation index system to evaluate the teaching ability of college PE teachers [10]. Jiang and Luo adopted empirical analysis method to discuss the PE teaching in higher vocational colleges and its evaluation methods from the perspective of motor development studies [11]. Heemsoth and Kleickmann used actual teaching examples to discuss how to improve the PE teaching effect through planning and self-control [12]. Shahril et al. studied the reliability and validity of the performance evaluation of future PE teachers' teaching and learning processes based on the ISO test, which has a good role in promoting the quality of physical education [13]. However, considering that the college PE teaching quality is constrained by a variety of influencing factors and its evaluation is a complex systematic decision-making analysis project, during the decision-making analysis process, not only the completeness of the college PE teaching quality evaluation system should be taken into consideration, but also the fuzzy uncertainty of the evaluation information should be considered as well; in particular, since scholars analyze the evaluation methods of college PE teaching quality from different dimensions, their analysis focuses vary as well. To this end, combining with existing research results, this paper attempts to improve the evaluation system of college PE teaching quality, and proposes a college PE teaching quality evaluation model that can process the fuzzy and uncertain information, in the hopes of providing support for improving the PE teaching quality in colleges and universities.

The content of this paper includes 6 parts. The first part is an overview of the evaluation of college PE teaching quality; the second part analyzes the shortcomings existing in current college PE teaching; the third part establishes a new system for the evaluation of college PE teaching quality; the fourth part constructs a multi-attribute fuzzy evaluation model of college PE teaching quality; the fifth part analyzes the implementation strategies for improving college PE teaching quality; and the sixth part gives the conclusions.

\section{Shortcomings Existing in Current College PE Teaching}

\subsection{Incomplete curriculum system}

In higher education, PE teaching is a subject that emphasizes more on the integration of theory and practice; it requires not only the professional knowledge, the systematic theoretical basis, but also a scientific practice system. However, due to the neglect of school management team, the support for college PE teaching is insufficient in terms of manpower, material, and financial resources, and there's no systematic professional planning and management, which leads to a lack in excellent PE courses and the superficial analysis on the influence of the times and the society on PE teaching; moreover, the relevant works concerning PE teaching reform, teaching material compilation, teaching content improvement and teaching concept innovation relatively lag behind, 
which has resulted in great shortcomings in the systematicness of the college PE curriculum system.

\subsection{Inadequate faculty level}

At present, higher education generally tends to pay more attention to the development of science and engineering majors or some popular majors and disciplines. In the development planning of common colleges and universities, PE major is rarely taken as a key subject, which directly leads to inadequate faculty level, the hardware facilities of PE teaching are poor and the teaching level of the PE faculty is low. To improve the teaching quality of college PE lessons, enhancing the PE faculty level is the key link, and this requires the schools to increase investment in PE teaching, introduce highquality senior talents, and enhance the communication ability of professional PE talents.

\subsection{Unitary teaching form}

Current PE teaching in colleges and universities usually takes the exam-oriented teaching form, from curriculum setting to course planning, it's mostly implemented in the traditional teaching mode; when it comes to the quality-oriented education, there're certain limitations that make the current PE teaching unable to fully consider the students' personal interests and specialties, especially in the current diversified social development stage, the single PE teaching form lacks the necessary innovative and revolution capabilities, resulting in large limitations in the personalized cultivation of the PE talents.

\subsection{The evaluation attaches more weight to result than to process}

From the perspective of the characteristics of PE major, its teaching process can better reflect students' comprehensive qualities such as physical fitness, sports ability, learning ability and innovation ability. However, the current PE major evaluation tends to focus only on the test scores or the sports skills, while ignoring the learning process of PE major, and such evaluation methods that focus more on result rather than process often leads to one-sided evaluation results which are neither logic nor systematic. Especially when the evaluation subject is a single subject, due to the inevitable subjective factors, the evaluation results of the PE teaching quality can hardly reflect the real situation, failing to provide proper guidance that it's supposed to provide.

\subsection{The teaching concept and mode need to be innovated}

Although the teaching mode of college PE has gradually begun to transform to quality-oriented education, currently, it is still exam-oriented, which requires the corresponding teaching concept and mode to be further reformed and upgraded. The PE teaching mode should not be limited to the traditional form, but be improved dynamically combining with the development trend of the times; moreover, we ought to 
bravely break the traditional teaching mode and adapt to the requirements of the qualityoriented PE teaching, that is, to reform the traditional classroom teaching to the teaching mode that combines classroom with extracurricular activities, to change the theorybased teaching into the teaching mode that combines theories with practice, to convert the skill-focused teaching into the teaching mode that improves the comprehensive sports quality, and to transform the passive teaching to the active teaching mode that increases students' interests and enthusiasm for learning.

\subsection{The classroom performance of PE teachers needs to be improved}

The classroom teaching of college PE plays a very important role in the teaching of sports knowledge, and the classroom performance of PE teachers directly affects students' sports knowledge reception and absorption. However, current college PE classroom teaching still has a few deficiencies such as the classroom teaching is hidebound and less interactive; the teaching content is outdated, not systematic, and poorly planned; the classroom teaching methods are less intelligent, the explanation of complex actions and analysis of sports skills are not good; besides, the PE teachers' teaching attitude, professional literacy and teaching manner also have an impact on the classroom teaching effect.

\section{A New College PE Teaching Quality Evaluation System}

To make the evaluation results of college PE teaching quality more reliable, it's necessary to evaluate and analyze the teaching quality of college PE from a more comprehensive perspective. Considering that different evaluation perspectives generally have respective emphases, this paper chooses to evaluate and analyze the college PE teaching quality from three dimensions of the management level's perspective, the teachers' perspective, and the students' perspective.

\section{1 $S_{1}$, the sub-level evaluation system of college PE teaching quality based on the perspective of the management}

Evaluation system $S_{I}$ mainly investigates the impact of the college's basic PE facilities on the teaching quality from the perspective of the management. This paper conducts the comprehensive evaluation from the following aspects: the comprehensive professional skills of PE teachers $s_{11}$, the completeness of college PE course $s_{12}$, the reform ability of college PE teaching $s_{13}$, the construction of software and hardware facilities and investment in PE teaching $s_{14}$, and the integration ability of PE teaching in industrycollege-research cooperation $s_{15}$. 


\section{2 $S_{2}$, the sub-level evaluation system of college PE teaching quality based on} the perspective of teachers

Evaluation system $S_{2}$ mainly investigates the impact of the execution of PE teaching process on the PE teaching quality from the perspective of the education experts. This paper conducts the comprehensive evaluation from the following aspects: the novelty and richness of PE teaching content $s_{21}$, the rationality and scientificity of PE teaching plan (or syllabus) $s_{22}$, the advantages and adaptability of PE teaching methods $s_{23}$, the diversity and intelligent-level of PE teaching methods $s_{24}$, the completion of PE teaching tasks $s_{25}$, and the teaching performance and effect of PE class $s_{26}$.

\section{3 $S_{3}$, the sub-level evaluation system of college PE teaching quality based on the perspective of students}

Evaluation system $S_{3}$ mainly investigates the implementation results of college PE teaching from the perspective of students. This paper conducts the comprehensive evaluation from the following aspects: students' pass rate in comprehensive sports quality assessment $s_{31}$, students' excellent rate in comprehensive sports quality assessment $s_{32}$, students' innovation ability $s_{33}$, students' autonomous learning ability $s_{34}$, students' social service ability $s_{35}$, and students' rewards in sports competitions $s_{36}$.

\section{Multi-Attribute Fuzzy Evaluation Model of College PE Teaching Quality}

\subsection{Standardization of evaluation indicators}

According to the college PE teaching quality evaluation systems constructed in previous sections above, the evaluation indicators are diverse, and the initial data obtained may have different dimensions. To make the evaluation more accurate, it's necessary to standardize the evaluation indicators; to make the standardization process universal, it is assumed that there are $m$ evaluation objects and $n$ evaluation indicators in the college PE teaching quality evaluation, and there are two types of evaluation indicators: the benefit type and the cost type. If the initial data of the i-th evaluation object with respect to the j-th evaluation indicator is $V_{i}^{j}=\left[v_{i}^{j}(\right.$ lef $), v_{i}^{j}($ rig $\left.)\right], v_{i}^{j}(l e f) \leq v_{i}^{j}($ rig $)$, when the evaluation indicator is a benefit-type indicator, the corresponding standardized value is:

$$
\begin{aligned}
& U_{i}^{j}=\left[u_{i}^{j}(\text { lef }), u_{i}^{j}(r i g)\right] \\
& =\left[\frac{v_{i}^{j}(\text { lef })-\min _{1 \leq i \leq m} v_{i}^{j}(\text { lef })}{\max _{1 \leq i \leq m} v_{i}^{j}(r i g)-\min _{1 \leq i \leq m} v_{i}^{j}(\text { lef })}, \frac{v_{i}^{j}(r i g)-\min _{1 \leq i \leq m} v_{i}^{j}(\text { lef })}{\max _{1 \leq i \leq m} v_{i}^{j}(r i g)-\min _{1 \leq i \leq m} v_{i}^{j}(\text { lef })}\right]
\end{aligned}
$$


When the evaluation indicator is a cost-type indicator, the corresponding standardized value is:

$$
\begin{aligned}
& U_{i}^{j}=\left[u_{i}^{j}(\text { lef }), u_{i}^{j}(\text { rig })\right] \\
& =\left[\frac{\max _{1 \leq i \leq m} v_{i}^{j}(\text { rig })-v_{i}^{j}(\text { rig })}{\max _{1 \leq i \leq m} v_{i}^{j}(\text { rig })-\min _{1 \leq i \leq m} v_{i}^{j}(\text { lef })}, \frac{\max _{1 \leq i \leq m} v_{i}^{j}(r i g)-v_{i}^{j}(\text { lef })}{\max _{1 \leq i \leq m} v_{i}^{j}(r i g)-\min _{1 \leq i \leq m} v_{i}^{j}(\text { lef })}\right]
\end{aligned}
$$

It can be seen that the accurate value processing is a special form of the current analysis situation, moreover, after standardization, all evaluation indicators have a unified metric, and their value range is within 0-1.

\subsection{Implementation of GRA}

If there are multiple evaluation objects in the college PE teaching quality evaluation, each evaluation object has a corresponding standardized value for each evaluation indicator. Considering that the values of evaluation indicators may be fuzzy values, then with respect to the evaluation indicators, the evaluation objects would form a fuzzy sequence containing uncertain information. According to GRA theories, GRA can effectively solve such multi-attribute decision-making analysis problems with uncertain information. Targeting at the college PE teaching quality evaluation problem studied in this paper, the GRA process can be realized through the following steps.

First, since different evaluation indicators generally have different weights, to enable the evaluation results to better reflect the degrees of the impact of different indicators, it is necessary to obtain the weights of the corresponding evaluation indicators. The AHP method has advantages such as simple calculation and reliable [14-16], for this reason, by applying AHP, the weights of the evaluation indicators of college PE teaching quality could be obtained.

Second, after obtaining the m evaluation objects' values with respect to the n evaluation indicators, the evaluation indicators' maximum gray sequence $\boldsymbol{U}_{\text {max }}$ and minimum gray sequence $\boldsymbol{U}_{\text {min }}$ could be obtained as follows:

$$
\begin{gathered}
\mathbf{U}_{\max }=\left\{U_{\max -i}^{j} \mid 1 \leq j \leq n\right\}=\left\{\max _{1 \leq i \leq m}\left(U_{i}^{j}\right) \mid 1 \leq j \leq n\right\} \\
\mathbf{U}_{\min }=\left\{U_{\min -i}^{j} \mid 1 \leq j \leq n\right\}=\left\{\min _{1 \leq i \leq m}\left(U_{i}^{j}\right) \mid 1 \leq j \leq n\right\}
\end{gathered}
$$

In particular, if a value of an evaluation indicator is a fuzzy value, namely $U_{i}^{j}=$ $\left[u_{i}^{j}(l e f), u_{i}^{j}(r i g)\right]$, then there are:

$$
\begin{aligned}
& U_{\max -i}^{j}=\left[u_{\max -i}^{j}(\text { lef }), u_{\max -i}^{j}(\text { rig })\right]=\left[\max _{1 \leq i \leq m}\left(u_{i}^{j}(\text { lef })\right), \max _{1 \leq i \leq m}\left(u_{i}^{j}(\text { rig })\right)\right] \\
& U_{\min -i}^{j}=\left[u_{\min -i}^{j}(\text { lef }), u_{\min -i}^{j}(\text { rig })\right]=\left[\min _{1 \leq i \leq m}\left(u_{i}^{j}(\text { lef })\right), \min _{1 \leq i \leq m}\left(u_{i}^{j}(\text { rig })\right)\right]
\end{aligned}
$$


Third, based on the maximum gray sequence $\boldsymbol{U}_{\max }^{j}$ and the minimum gray sequence $\boldsymbol{U}_{\min }^{j}$ of the evaluation indicators, the fuzzy distances $D_{\max -i}^{j}$ and $D_{\min -i}^{j}$ between the $\mathrm{i}$-th evaluation object with respect to the $\mathrm{j}$-th evaluation indicator and $U_{\max -i}^{j}$ and $U_{\min -i}^{j}$ can be obtained. According to the calculation model of fuzzy distance [17-20], the common fuzzy distance has two forms: Euclidean distance and Hamming distance, namely:

$$
\begin{aligned}
& \left\{\begin{array}{l}
D_{\max -i}^{j}=\frac{\mid u_{i}^{j}(\text { lef })-u_{\max -i}^{j}(l e f)|+| u_{i}^{j}(\text { rig })-u_{\max -i}^{j}(\text { rig }) \mid}{2} \\
\text { or } \\
D_{\max -i}^{j}=\sqrt{\frac{\mid u_{i}^{j}(\text { lef })-\left.u_{\max -i}^{j}(\text { lef })\right|^{2}+\mid u_{i}^{j}(\text { rig })-\left.u_{\max -i}^{j}(\text { rig })\right|^{2}}{2}}
\end{array}\right. \\
& \left\{\begin{array}{l}
D_{\min -i}^{j}=\frac{\left|u_{i}^{j}(l e f)-u_{\min -i}^{j}(l e f)\right|+\mid u_{i}^{j}(\text { rig })-u_{\min -i}^{j}(\text { rig }) \mid}{2} \\
\text { or } \\
D_{\min -i}^{j}=\sqrt{\frac{\left|u_{i}^{j}(l e f)-u_{\min -i}^{j}(l e f)\right|^{2}+\mid u_{i}^{j}(r i g)-\left.u_{\min -i}^{j}(\text { rig })\right|^{2}}{2}}
\end{array}\right.
\end{aligned}
$$

Then, based on the constructed fuzzy distance and the gray system theory [21-25], we could obtain the gray relation coefficients $\xi_{\max -i}^{j}$ and $\xi_{\min -i}^{j}$ between the i-th evaluation object with respect to the j-th evaluation indicator and $\boldsymbol{U}_{\max }$ and $\boldsymbol{U}_{\min }$ as:

$$
\begin{aligned}
& \xi_{\max -i}^{j}=\frac{\min _{i} \min _{j} D_{\max -i}^{j}+\rho \max _{i} \max _{j} D_{\max -i}^{j}}{D_{\max -i}^{j}+\beta \max _{i} \max _{j} D_{\max -i}^{j}} \\
& \xi_{\min -i}^{j}=\frac{\min _{i} \min _{j} D_{\min -i}^{j}+\rho \max _{i} \max _{j} D_{\min -i}^{j}}{D_{\min -i}^{j}+\beta \max _{i} \max _{j} D_{\min -i}^{j}}
\end{aligned}
$$

where, $\rho$ is the identification coefficient, its value generally takes 0.5 .

Then, considering the weights of the evaluation indicators, it's assumed that the weight of the $\mathrm{j}$-th evaluation indicator is $w_{j}$, then the weighted gray relation degrees $\phi_{\max -i}$ and $\phi_{\min -i}$ between the i-th evaluation object with respect to the $\mathrm{j}$-th evaluation indicator and $\boldsymbol{U}_{\max }$ and $\boldsymbol{U}_{\min }$ are:

$$
\varphi_{\max -i}=\sum_{j=1}^{n}\left(w_{j} * \xi_{\max -i}^{j}\right)
$$




$$
\varphi_{\min -i}=\sum_{j=1}^{n}\left(w_{j} * \xi_{\min -i}^{j}\right)
$$

Furthermore, the comprehensive weighted gray relation degree $\theta_{i}$ of the i-th evaluation object is:

$$
\theta_{i}=\frac{\left(\varphi_{\max -i}\right)^{2}}{\left(\varphi_{\max -i}\right)^{2}+\left(\varphi_{\min -i}\right)^{2}}
$$

Finally, the multi-attribute decision analysis principle for the college PE teaching quality evaluation could be established, that is, if it satisfies:

$$
\theta_{k}=\max \left\{\theta_{1}, \theta_{2}, \cdots, \theta_{i}, \cdots, \theta_{m}\right\}, \quad 1 \leq k, i \leq m
$$

Then it indicates that the k-th evaluation object of the college PE teaching quality evaluation has the best PE teaching quality.

In conclusion, the realization process of the multi-attribute fuzzy evaluation of college PE teaching quality is shown as Figure 1.

\section{$5 \quad$ Implementation Strategies for College PE Teaching Quality Improvement}

After the multi-attribute fuzzy evaluation model was adopted for analysis, the PE teaching quality of the evaluation objects could be judged. For objects with poor PE teaching quality, targeted implementation measures should be taken to improve their PE teaching quality, this study proposes the following implementation strategies:

\subsection{Strengthen the basic conditions of college PE teaching}

The construction of basic guarantee conditions for PE teaching in colleges and universities is an important basis for improving the PE teaching quality in colleges and universities, and it provides the most fundamental guarantee measures for the smooth implementation of PE teaching in colleges and universities. This study proposes several aspects that should be paid attention to: first, increase investment in college PE teaching and research, so that the implementation of PE teaching could have sufficient operation funds; second, upgrade the software and hardware facilities for college PE teaching, such as the sports venues, classrooms, research rooms and sports equipment and related supporting infrastructure, etc.; third, strengthen the management of college PE teaching, and form a set of highly adaptable PE teaching regulations and norms to provide instructions for the smooth implementation of PE teaching. 
Paper-A Multi-Attribute Fuzzy Evaluation Model for the Teaching Quality of Physical Education..

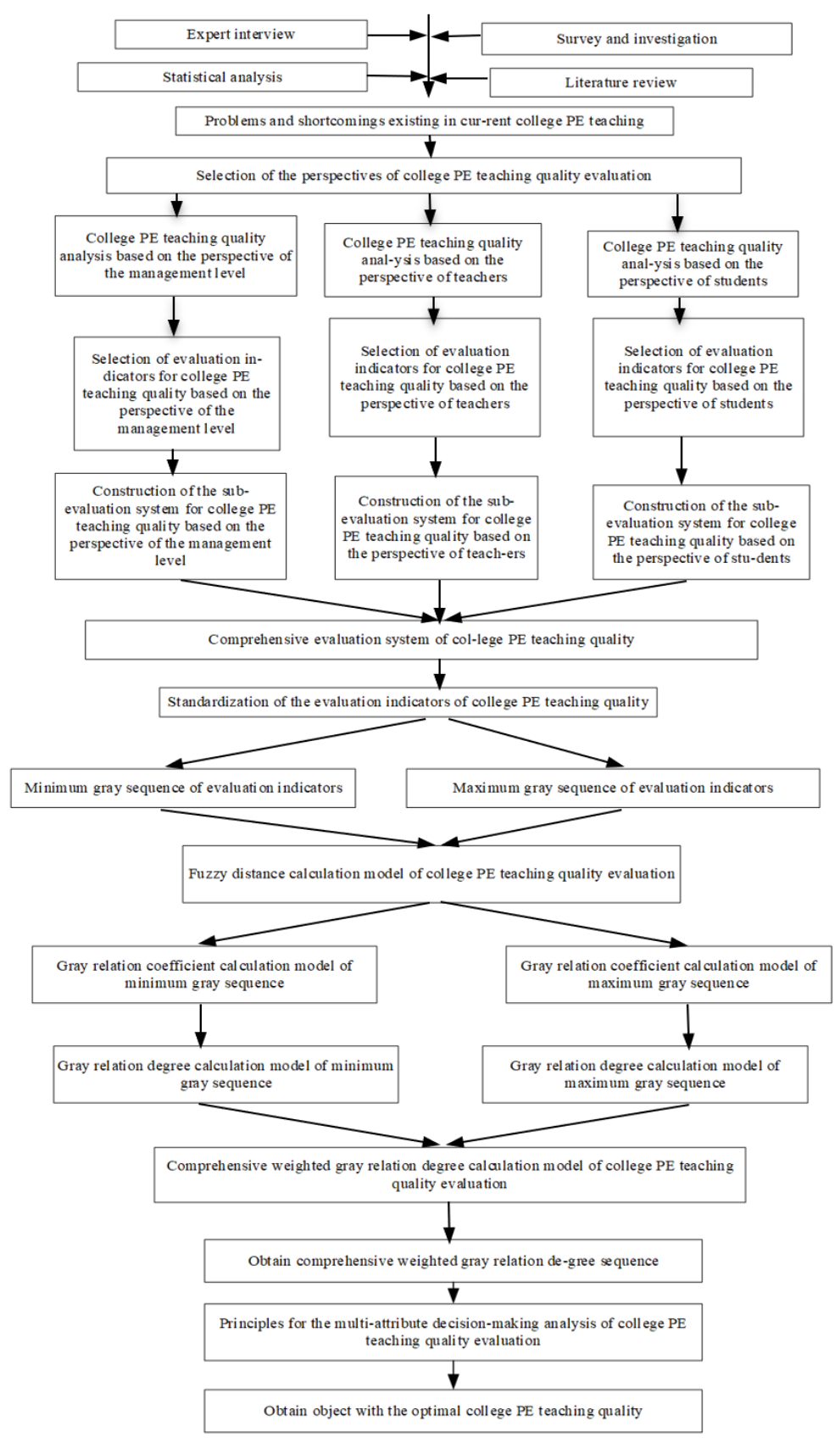

Fig. 1. Realization process of multi-attribute fuzzy evaluation of college PE teaching quality 


\subsection{Improve college PE faculty level}

Constructing a high-level PE teaching faculty in colleges and universities is an important link in the improvement of college PE teaching quality, and it is also an important implementation content for the execution process of college PE teaching. This paper proposes to improve college PE faculty level from the following aspects: first, enhance the comprehensive professional skills of PE teachers so that the college faculty could have a higher level of expertise; second, build a PE teaching talent team with good growth potential, attention should be paid to the cultivation of senior teachers and middle and young-aged teachers with higher education levels, so that the development of PE teachers could be sustainable; third, form a PE curriculum system with characteristics of higher education, especially the construction of excellent courses; fourth, increase the communication and exchange between senior talents of college PE majors, enhance their abilities to impart PE courses by sharing the sports knowledge and teaching experience.

\subsection{Upgrade PE teaching concept and transform teaching mode}

The modern PE teaching in colleges and universities has gradually shifted to the quality-oriented teaching mode, which requires the college PE teaching to implement the quality-oriented education. To this end, it is necessary to transform the traditional passive PE teaching concept to the direction of people-oriented, comprehensive, open, diversified, and personalized, so that the traditional exam-oriented teaching mode could be truly changed to the quality-oriented teaching mode. For the existing outdated teaching content, courses, and methods, targeted reform and innovation measures should be carried out so that they could better adapt to the cultivation demands and goals of modern college PE teaching. Moreover, the PE courses should be more systematic and complete, the PE teaching content should be updated and novel, the PE teaching means should be more diverse and intelligent, and the PE teaching methods should be more adaptable.

\subsection{Improve college students' interests, enthusiasm and participation in PE learning}

Interest and enthusiasm are two important factors to improve the learning effect of college students, especially for the study of PE courses, as more attention is paid to the combination of theoretical knowledge and practical experience, it requires college students to invest more interest and enthusiasm in learning so that it can facilitate their reception and absorption of sports knowledge, motions and skills. How can we increase the interest, enthusiasm and participation of college students in sports learning? This paper proposes to pay attention to the following aspects: first, increase the interestingness and interactivity of college PE class, many sports knowledge need to be verified via practice, if there's no interaction or interesting point, the PE teaching content would be very dull; second, improve the participation and initiative of college students in sports, only by participating in the PE teaching practice more often can students have a 
more profound understanding of the professional sports knowledge; third, pay attention to cultivate college students' abilities in innovation and autonomous learning in terms of sports learning, so that it'll be more conductive to their reception and absorption of sports knowledge.

\subsection{Strengthen college PE teaching's abilities in industry-college-research cooperation and social service}

The goal of higher education is to cultivate senior professionals who can adapt to the social development. In this sense, college PE teaching should pay more attention to the improvement of the comprehensive quality of the sports professionals; however, since PE teaching has both theoretical and practical features, in the college PE teaching process, the integration of theory and practice is a key path for the improvement of PE teaching quality. The industry-college-research mode has a very important role in promoting the cultivation of senior talents in colleges and universities, and it has a good application effect in the implementation of many higher education majors, therefore, it provides important guidance and reference for the implementation of college PE teaching. In terms of the implementation of the industry-college-research mode, this paper proposes to pay attention to the following aspects: first, combine with the actual situation of related enterprises and employers in the industry, and enhance college students' practical abilities; second, the deep-level integration with sports knowledge, and deepen college students' professional theoretical knowledge; third, combine with the scientific research of PE majors, and enhance college students' abilities in independent scientific research and problem-solving. Through the implementation of industry-college-research cooperation, the college PE teaching could better serve the society.

\section{Conclusion}

The research results of this paper are mainly reflected in the following aspects:

1. This paper conducted a theoretical analysis on the shortcomings existing in current college PE teaching, then on this basis, it proposed several implementation strategies to improve the college PE teaching quality, which is of important guiding significance.

2. This paper constructed a new college PE teaching quality evaluation system, and analyzed the problem of college PE teaching quality evaluation from the perspectives of management, teachers, and students; and it realized theoretical innovation of the evaluation system.

3. This paper gave a multi-attribute fuzzy evaluation model for the evaluation of college PE teaching quality, which achieved the quantitative analysis of the evaluation of college PE teaching quality, and it has good adaptability in practical applications. 


\section{$7 \quad$ References}

[1] Osman, A.S.A., Faizal Khan, Z. (2019). Novel methodology for arbitration of talented students using an electronic system: A higher education perspective, International Journal of Emerging Technologies in Learning, 14(21): 250-257. https://doi.org/10.3991/ijet.v14 i21.10916

[2] Ashour, A.F. (2020). Design responsibility and sustainability in education. International Journal of Design \& Nature and Ecodynamics, 15(1): 129-133. https://doi.org/10.18280/ ijdne. 150117

[3] Lassen, A.K., Seth, E.H., Tollnes, T. (2018). Enhancing learning outcomes by introducing $\mathrm{BIM}$ in civil engineering studies - experiences from a university college in Norway. International Journal of Sustainable Development and Planning, 13(1): 62-72. https:// doi.org/10.2495/sdp-v13-n1-62-72

[4] Liu, S. L., Yin, Y. T., Zhou, W. F. (2020). On Application Mini MOOC O2O Teaching Model Based on College Physical Education. Journal of Southwest China Normal University (Natural Science Edition), 45(4): 97-102. https://doi.org/10.13718/j.cnki.xsxb.2020.04.017

[5] Pan, L. (2019). A big data-based data mining tool for physical education and technical and tactical analysis, International Journal of Emerging Technologies in Learning, 14(22): 220231. https://doi.org/10.3991/ijet.v14i22.11345

[6] Thorburn, M. (2018). John Dewey, subject purposes and schools of tomorrow: A centennial reappraisal of the educational contribution of physical education. Learning, Culture and Social Interaction, 19: 22-28. https://doi.org/10.1016/j.lcsi.2018.04.001

[7] Forey, G. (2019). Lok Ming Eric Cheung. The benefits of explicit teaching of language for curriculum learning in the physical education classroom. English for Specific Purposes, 54: 91-109. https://doi.org/10.1016/j.esp.2019.01.001

[8] Gao, H. (2020). Analysis on the Diversification Model of College Physical Education Evaluation. BULLETIN OF SPORT SCIENCE AND TECHNOLOGY, 28(4): 82-83. https://doi.org/ 10.19379/j.cnki.issn.1005-0256.2020.04.030

[9] Qin, M., Li, Z. H., Kong, L. M. (2020). Research on the Reform of College Physical Education Teaching Evaluation Based on DEA Model. Bulletin of Sport Science And Technology, 28(5): 75-76+82. https://doi.org/10.19379/j.cnki.issn.1005-0256.2020.05.035

[10] Zhao, W. K., Wang, Z. Q. (2018). Construction of Evaluation Indicator System of Teaching Ability of Physical Education Teachers in Colleges and Universities. Sports Research and Education, 33(6): 69-74. https://doi.org/10.16207/j.cnki.2095-235x.2018.06.014

[11] Jiang, L., Luo, Y. (2020). Practical Research on Vocational Ways under Motor Development - Take Running and Jumping PE Teaching and Evaluation as Examples. Bulletin of Sport Science and Technology, 28(3): 13-14+17. https://doi.org/10.19379/j. cnki.issn.1005-0256.2020.03.006

[12] Heemsoth, T., Kleickmann, T. (2018). Learning to plan self-controlled physical education: Good vs. problematic teaching examples. Teaching and Teacher Education, 71: 168-178. https://doi.org/10.1016/j.tate.2017.12.021

[13] Shahril, M. I. B., Salimin, N. B., Elumalai, G. (2015). The Validity and Reliability of ISO Test towards the Performance Assessment of Future Physical Education Teachers in Teaching and Learning Process. Procedia - Social and Behavioral Sciences, 195: 814-820. https://doi.org/10.1016/j.sbspro.2015.06.184

[14] Baffoe, G. (2019). Exploring the utility of Analytic Hierarchy Process (AHP) in ranking livelihood activities for effective and sustainable rural development interventions in developing countries. Evaluation and Program Planning, 72: 197-204. https://doi.org/10. $\underline{1016 / \text { j.evalprogplan.2018.10.017 }}$ 
[15] Improta, G., Russo, M. A., Triassi, M., Converso, G., Murino, T., Santillo, L.C. (2018). Use of the AHP methodology in system dynamics: Modelling and simulation for health technology assessments to determine the correct prosthesis choice for hernia diseases. Mathematical Biosciences, 299: 19-27. https://doi.org/10.1016/j.mbs.2018.03.004

[16] Butdee, S., Phuangsalee, P. (2019). Uncertain risk assessment modelling for bus body manufacturing supply chain using AHP and fuzzy AHP. Procedia Manufacturing, 30: 663670. https://doi.org/10.1016/j.promfg.2019.02.094

[17] Taheri, R., Ghahramani, M., Javidan, R., Shojafar, M., Pooranian, Z., Conti, M. (2020). Similarity-based Android malware detection using Hamming distance of static binary features. Future Generation Computer Systems, 105: 230-247. https://doi.org/10.1016/j. future.2019.11.034

[18] Miklós, I., Smith, H. (2019). The computational complexity of calculating partition functions of optimal medians with Hamming distance. Advances in Applied Mathematics, 102: 18-82. https://doi.org/10.1016/j.aam.2018.09.002

[19] Bukovšek, D. K., Laffey, T., Šmigoc, H. (2020). Completely positive factorizations associated with Euclidean distance matrices corresponding to an arithmetic progression. Linear Algebra and its Applications, 597: 113-132. https://doi.org/10.1016/j.laa.2020.03. $\underline{022}$

[20] Sánchez, A. D. B., Lavor, C. (2020). On the estimation of unknown distances for a class of Euclidean distance matrix completion problems with interval data. Linear Algebra and its Applications, 592: 287-305. https://doi.org/10.1016/j.laa.2020.01.036

[21] Škrinjarić, T. (2020). Dynamic portfolio optimization based on grey relational analysis approach. Expert Systems with Applications, 147: 1-15. https://doi.org/10.1016/i.eswa. 2020.113207

[22] Moonchai, S., Chutsagulprom, N. (2020). Short-term forecasting of renewable energy consumption: Augmentation of a modified grey model with a Kalman filter. Applied Soft Computingt, 87: 1-13. https://doi.org/10.1016/j.asoc.2019.105994

[23] Sarraf, F., Nejad, S. H. (2020). Improving performance evaluation based on balanced scorecard with grey relational analysis and data envelopment analysis approaches: Case study in water and wastewater companies. Evaluation and Program Planning, 79: 1-11. https://doi.org/10.1016/j.evalprogplan.2019.101762

[24] Kanchana, J., Prasath, V., Krishnaraj, V., Geetha, P. (2019). Multi response optimization of process parameters using grey relational analysis for milling of hardened Custom 465 steel. Procedia Manufacturing, 30: 451-458. https://doi.org/10.1016/j.promfg.2019.02.064

[25] Maghrabie, H. F., Beauregard, Y., Schiffauerova, A. (2019). Grey-based Multi-Criteria Decision Analysis approach: Addressing uncertainty at complex decision problems. Technological Forecasting and Social Change, 146: 366-379. https://doi.org/10.1016/j. techfore.2019.05.031

\section{Authors}

Yao Wang isfrom Cangzhou city Hebei Province. A master of education Yao Wang is now the teacher in the HR office of Cangzhou normal university. Vice president of Cangzhou Taekwondo Association. With level-1 social sports instructor certificate as well as 2nd class referee certificate of track and field, basketball, football, badminton, table tennis and martial arts, etc. Yaon Wang graduated in sport humanistic sociology 
from The Capital Institute of Physical Education in June 2016. Mainly studied the direction of physical education society and physical education teaching.

Chunyan Sun was born in Oct., 1977 in Cangzhou City, Hebei Province, China. He received B.A degree of traditional ethnic sports from Beijing Sport University in 1999 and M.A. degree in physical education from Beijing Sport University in 2017. He has started his teaching career in Cangzhou Normal College since Sept., 1999.

Ying Guo was born in Oct., 1979 in Cangzhou City, Hebei Province, China. She received B.A. degree of music education from Hebei Normal University in 2002 and M.A. degree of music education from Capital Normal University. She has started her teaching career in Cangzhou Normal College since 2002.

Article submitted 2020-11-07. Resubmitted 2020-11-30. Final acceptance 2020-12-01. Final version published as submitted by the authors. 